\title{
HORÁRIO DE OCORRÊNCIA DAS TEMPERATURAS MÍNIMAS ABSOLUTAS DO AR DIÁRIAS EM SÃO PAULO, SP
}

\author{
Rogério Rozolen Alves $^{(\mathrm{a})}$, Emerson Galvani ${ }^{(\mathrm{b})}$ \\ ${ }^{(a)}$ Departamento de Geografia/FFLCH/Universidade de São Paulo rroz@usp.br \\ (b) Departamento de Geografia/FFLCH/Universidade de São Paulo, egalvani@usp.br
}

\section{Eixo:3.Climatologia em diferentes níveis escalares: mudanças e variabilidades}

\begin{abstract}
Resumo
O trabalho avalia os horários de maior frequência de ocorrênciade temperaturas mínimas diárias em São Paulo (SP) baseado nos dados da Estação Meteorológica Automática,

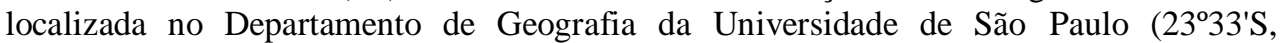
$46^{\circ} 43^{\prime} \mathrm{W}$ ).Utilizou-se de uma série de dados do período de 2008 a 2016, com registros horários totalizando 5046 observações. Os resultados demonstram que há maior predominância de ocorrência das temperaturas mínimas diárias entre as 5 h00min e 6h00min (23,5\% em relação ao total). Contudo, observa-se que entre as $23 \mathrm{~h} 00 \mathrm{~min}$ e Oh00min locais, há ocorrência de eventos de temperaturas mínimas, com 10,1\%, fato que pode estar associado a influência da maritimidade impulsionada pela brisa marítima em função da proximidade da área de estudo com o oceano Atlântico.
\end{abstract}

Palavras chave: Resfriamento noturno, brisa marítima, frequência de ocorrência.

\section{Introdução}

A taxa de resfriamento noturno expressa as perdas radiativas da superfície terrestre evidenciando estreita relação entre esses controles do clima. As noites com cobertura de céu limpo, com elevadas perdas radiativas, resultam em temperaturas mínimas absolutas do ar mais reduzidas que aquelas com cobertura de céu nublado. A taxa de resfriamento noturno, para o caso específico da cidade de São Paulo, em noite com céu limpo foi da ordem de $-0,5^{\circ} \cdot \mathrm{h}^{-1}$, enquanto em noites de céu nublado a temperatura mínima do ar foi próxima aquela registrada após o ocaso do sol (Galvani e Lima, 2012). A temperatura mínima do ar, registrada em abrigo meteorológico, ocorre poucos instantes antes do nascer do sol, portanto depende de latitude, da época do ano, e também da longitude do local. A ocorrência desses valores instantes antes do nascer do sol, justifica-se por ser o momento de máxima perda de energia, na forma de onda longa, acumulada, desde o ocaso do sol até esse momento.

A Região Metropolitana de São Paulo (RMSP) situa-se no limite do Trópico de Capricórnio, localizada na latitude de $23^{\circ} 21^{\prime} \mathrm{S}$ e longitude de $46^{\circ} 44^{\prime} \mathrm{W}$. De acordo com Tarifa e Armani (2001, p.35), devido a esta localização, é influenciada por um clima de transição, entre os 
Climas Tropicais Úmidos de altitude, com período seco definido, e aqueles subtropicais, permanentemente úmidos, do Brasil meridional.

Segundo Monteiro (1973, p.122)

\begin{abstract}
Ao sul desta faixa temos a ver com um clima regional em latitude subtropical, permanentemente úmido pela atividade frontal. Mesmo nos anos de atuação mais reduzida do ar polar, a sua participação não é inferior a $40 \%$, podendo elevar-se a $75 \%$ nos anos de maior atividade. Ao norte define-se com maior ou menor intensidade a existência de um período seco, coincidente com o Outono-Inverno, embora isto se apague no litoral. A menor penetração do ar polar no setor setentrional reduz a quantidade de chuvas frontais de sul para norte, conduz o mais das vezes ao bom tempo (MONTEIRO, 1973).
\end{abstract}

Caracteriza-se assim esta transição zonal como sendo de alternância de estações (quente-úmida e fria-seca), com bruscas variações dos tipos de tempo no município de São Paulo. Alguns estados atmosféricos podem ter intensidade elevada de aquecimento ou resfriamento em períodos de curta duração (dias a semanas).

De acordo com López (2001) em São Paulo, na primavera ocorre maior nebulosidade, acompanhado de maior penetração de frentes polares. No verão, a amplitude térmica diária é baixa, mas durante a noite, o calor pode ser amenizado pela entrada de brisa marítima de Sudeste. No outono, diminuem os ventos intensos, e há maiores períodos de calmaria. No inverno, devido a predominância do Anticiclone Tropical Atlântico, exercendo alta pressão em superfície, há menor penetração de frentes frias no continente, diminuindo assim os ventos de Sul e Sudeste.

De acordo com as Normais Climatológicas do Instituto Nacional de Meteorologia (INMET, 1992) no período de 1961 a 1990, na Estação Meteorológica localizada no Mirante de Santana, podemos ter uma caracterização razoável do clima local da cidade de São Paulo. Os registros dos atributos meteorológicos revelam a existência de dois períodos bem definidos (quente e chuvoso de outubro a março e frio e menos chuvoso, de abril a setembro). No mês mais frio (julho) a média de temperatura é de $15,8^{\circ} \mathrm{C}$, enquanto o mês mais quente (fevereiro) tem média de $28^{\circ} \mathrm{C}$.

Camargo et al.(1993) avaliou as ocorrências de temperaturas mínimas absolutas para o Estado de São Paulo, utilizando uma série de trinta anos de dados, identificando as áreas de maior ocorrência de temperaturas baixas em níveis mensal e anual, com incidência de geada, dentre 20 municípios analisados no interior do estado. 
Blain et al. (2009) buscaram detectar tendências de elevação nas séries anuais de temperaturamínima, bem como a data inicial dessas prováveis alterações, em seis localidades do Estado de São Paulo, utilizando o teste estatístico de Mann-Kendall. Constatam que os fatores de escala local (urbanização) se sobrepõem aos de escala global na elevação das temperaturas médias anuais, nos municípios estudados.

Lucas et al. (2011) verificaram quais os horários de maior ocorrência de temperatura mínima no município de Santa Maria (RS) após análise de dados de um período de 9 anos.Concluíram que nos meses de outono e inverno as temperaturas mínimas diárias ocorrem com maior frequência às 8 h00min. Nos meses de primavera, a frequência de ocorrência é maior às $6 \mathrm{~h} 00 \mathrm{~min}$, e na estação do verão às 7 h00min.

Daronco et al. (2014) realizaram um trabalho considerando a ocorrência das temperaturas mínimas e máximas diárias em Santo Augusto, município do Rio Grande do Sul. O período de dados da pesquisa foi de 2010 a 2013, coletados junto ao INMET. A frequência dos horários das temperaturas extremas mínimas diárias variou entre as 6h00min e as 8h00min.

Neste trabalho, o objetivo consiste em avaliar o horário de ocorrência das temperaturas mínimas do ar registradas em abrigo meteorológico em uma serie temporal de 2008 a 2016 para a cidade de São Paulo.

\section{Procedimentos metodológicos}

No período analisado entre 2008 e 2016, trabalhou-se com 5046 dados de temperaturas mínimas. Os dados da Estação Meteorológica Automática do Departamento de Geografia (EMA) (latitude $23^{\circ} 33^{\prime} \mathrm{S}$, longitude $46^{\circ} 43^{\prime} \mathrm{W}$, altitude 739 )são registrados a cada 5 minutos. Porém, dentre o período analisado, há faltas de registros devido a problemas nos sensores. Por conta disto, apenas parte dos dados da série foram utilizados para este trabalho, como segue discriminado na tabela 01 .

De 2008 até 2015 foram utilizados dados registrados pelo sensor de temperatura HMP35C. A partir de maio de 2015, os registros foram obtidos do sensor Datalogger HT500, instalado em substituição ao anterior, devido a falhas técnicas. Ambos estavam acondicionados dentro do abrigo (modelo 41003-10 Plate Radiation Shield), da marca Campbell Scientific.

Tabela 01: Período de amostra dos dados de temperatura do ar da Estação Meteorológica AutomáticaExperimental (EMA) utilizados no trabalho, com os meses de registros e os meses com ausência de dados. Org.: autores. 


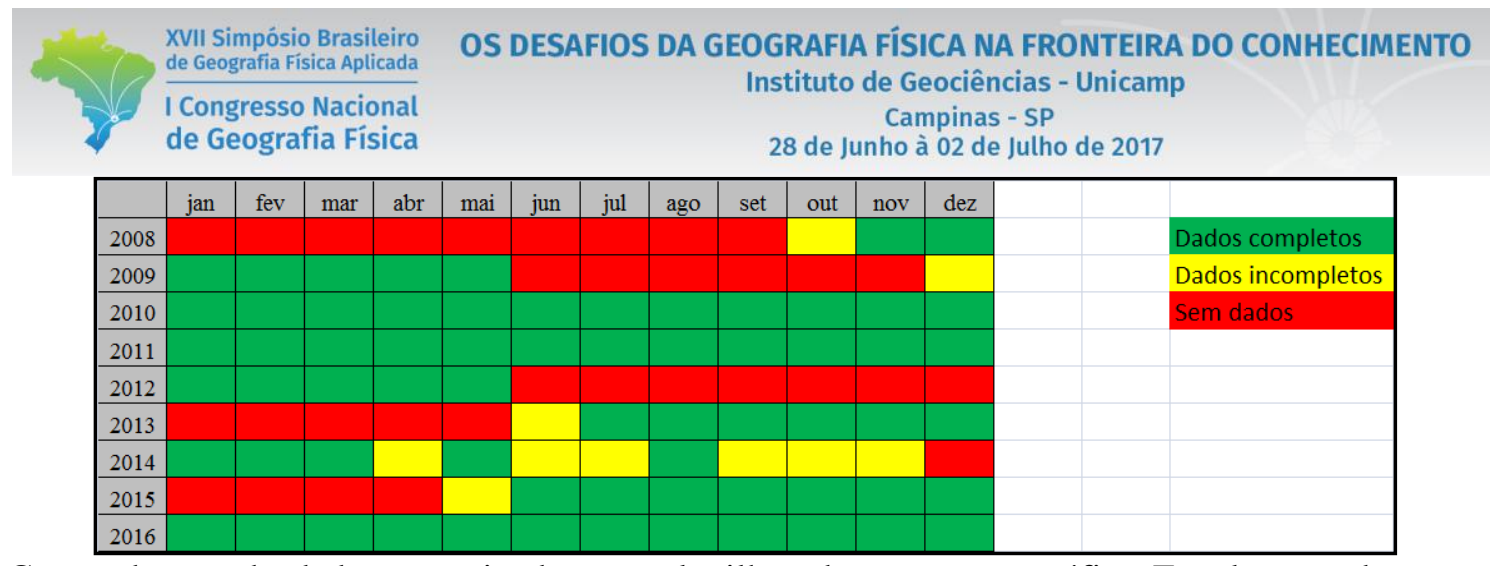

Com o banco de dados organizados em planilhas do programa gráfico Excel, procedeu-se a contagem dos horários das ocorrências de temperatura mínimas do ar. Apesar dos registros de temperatura ocorrerem a cada 5 minutos, os dados foram agrupados a cada 01 hora, para melhor visualização. Em seguida procedeu a representação gráfica dessas variáveis e o cálculo das frequências de ocorrências. Por vezes, ocorreram valores mínimos em mais de uma vez no dia, já que os dados são registrados a cada cinco minutos, aumentando a amostragem e valores coincidentes. Neste caso, todos os valores foram considerados válidos.

Para análise sazonal, foram agrupados os meses de acordo com a estação do ano, ou na transição entre elas, conforme segue: os meses de primavera (outubro, novembro e dezembro), verão (janeiro, fevereiro e março), outono (abril, maio e junho) e inverno (julho, agosto e setembro).

Para a análise de um estudo de caso, foi escolhido o dia 04/12/2016, por ser este um dos dias nos quais a temperatura mínima do ar ocorreu no período noturno. Assim, foi possível observar a marcha horária neste dia, e investigar quais outros atributos e controles poderiam ter influenciado na redução de temperatura ao longo do dia.

\section{Resultados e discussão}

\subsection{Marcha horária da temperatura}

Os dados de temperatura média, média das máximas e média das mínimas horárias da EMAforam analisados para o trabalho no período de 2008 a 2016. Na figura 01 é possível observar os valores de temperatura no período, onde as menores temperaturas são registradas entre $5 \mathrm{~h} 00 \mathrm{~min}$ e $6 \mathrm{~h} 00 \mathrm{~min}$, com os valores de $10,0^{\circ} \mathrm{C} ; 16,7^{\circ} \mathrm{C}$ e $21,5^{\circ} \mathrm{C}$ para as temperaturas mínimas, médias e máximas diárias. A média das máximas apresenta maior valor às $14 \mathrm{~h} 00 \mathrm{~min}$ $\left(32,7^{\circ} \mathrm{C}\right)$, enquanto que a média das mínimas alcança o maior registro às $12 \mathrm{~h} 00 \mathrm{~min}\left(14,6^{\circ} \mathrm{C}\right)$. 


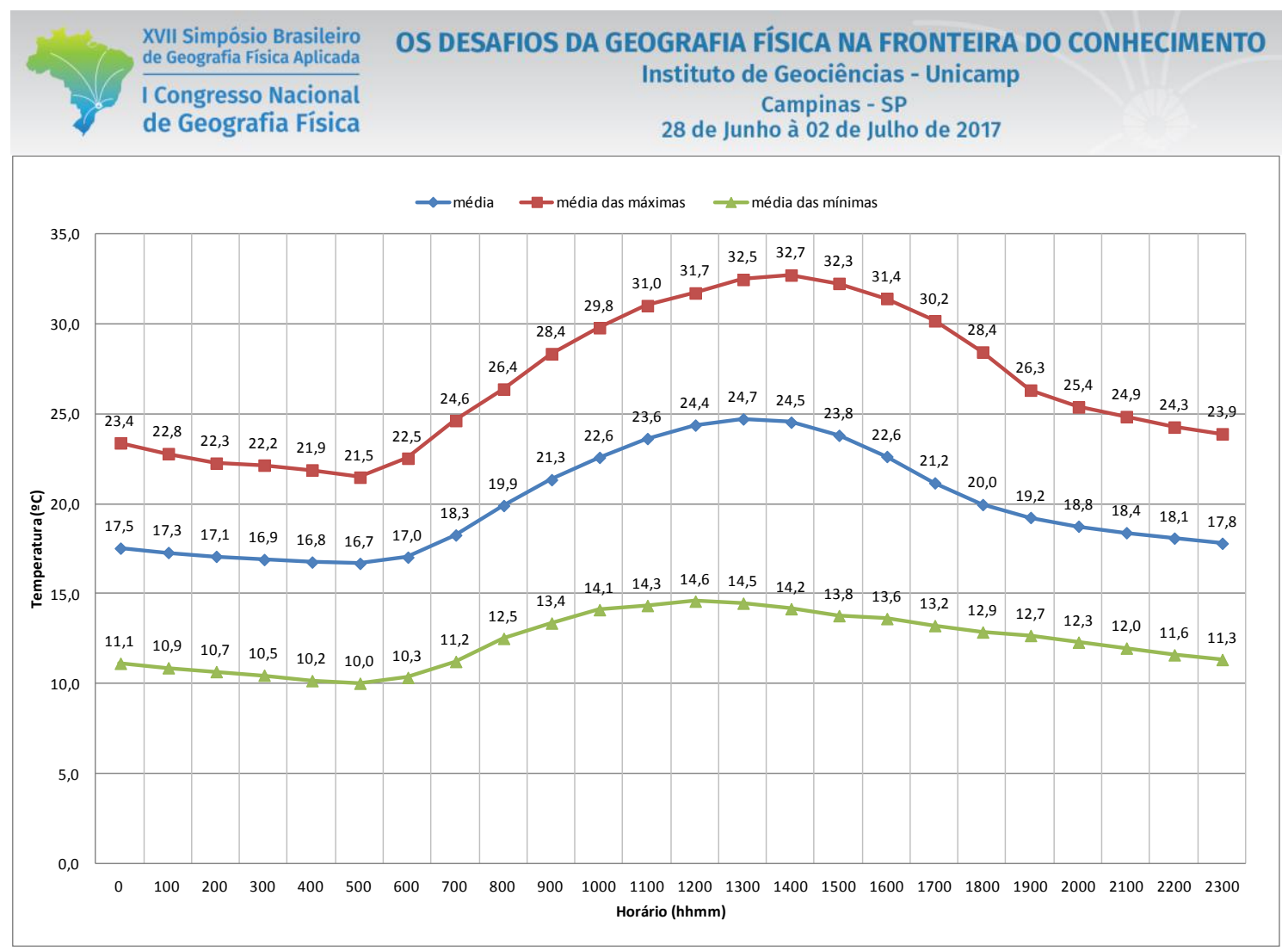

Figura 01:Marchahorária dos dados de temperatura do ar (média, máxima e mínima) da EMAdo Departamento de Geografia (Período de 2008 a 2016). Org.: autores.

Observa-se ainda na figura 01 que a ocorrência dos maiores resfriamentos, tanto para os valores de temperatura do ar mínima, media e máxima, ocorrem preferencialmente entre 04h00min e 06h00min.

\subsection{Análise anual}

Para o período analisado, observamos a maior ocorrência de temperaturas mínimas diárias no horário das 5 h00min, em 23,5\% dos dados. Das 4h00min às 7h00min é possível observar a ocorrência de 52\% dos registros (figura 02). Nota-se também que a partir das 19h00 há um aumento das ocorrências, culminando no intervalo entre $23 \mathrm{~h} 00 \mathrm{~min}$ e $0 \mathrm{~h} 00 \mathrm{~min}$, que registra 10,1\% das medições. Após este horário, há uma redução dos registros mínimos, entre as 0h00min e 3h00min, coincidindo com o maior resfriamento noturno conforme indicado na literatura.

Daronco et al. (2014) em seu trabalho, apurou que as temperaturas mínimas no município de Santo Angelo (RS) ocorrem entre 06h00mim e 08h00min, analisando os dados de 2010 a 2013. 


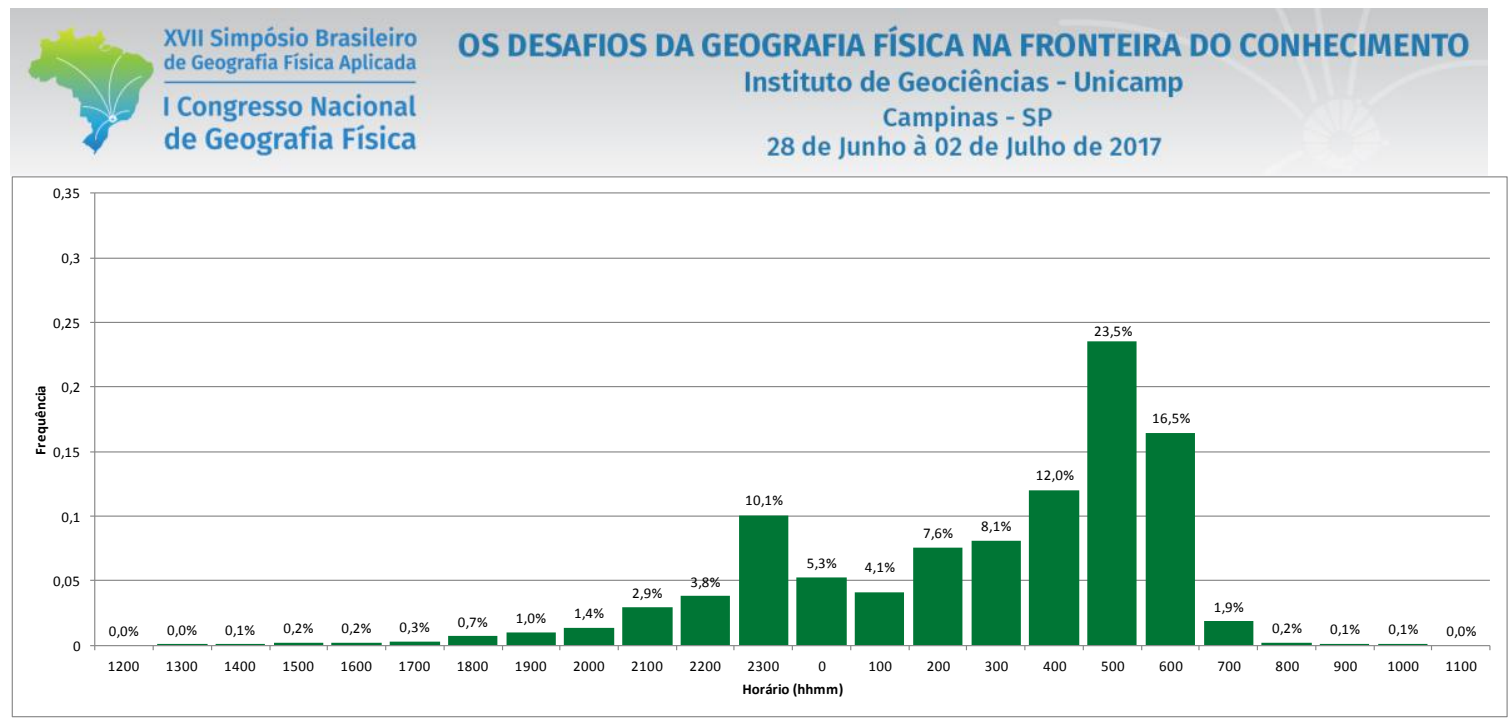

Figura 02: Percentual de ocorrências de temperaturas mínimas diárias na EME do Departamento de Geografia (2008 a 2016) no período anual.

\subsection{Análise sazonal}

Naestação da primavera houve 1544 registros e percentualmente, o horário entreas 5h00mine 6 h00min foi o de maior ocorrência de temperaturas mínimas, com 23,3\% do total, seguido do horário das 4h00min (16,8\%).(Figura 03).

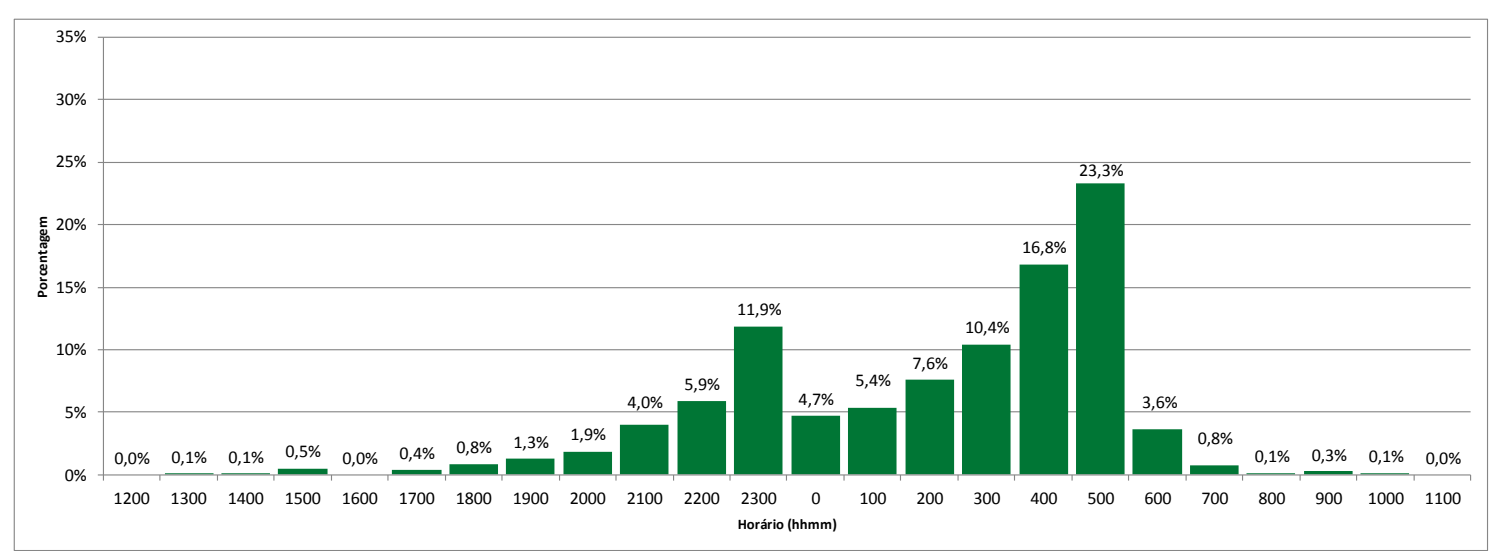

Figura 03: Percentual de ocorrências de temperaturas mínimas diárias na EMA do Departamento de Geografia (2008 a 2016), no período de primavera.

$\mathrm{Na}$ estação do verão foram registrados 1012 dados válidos. Percentualmente, conforme demonstra a figura 04 , o horário das 5 h00min foi o que teve a maior concentração das mínimas $(31,8 \%)$, com acentuada diferença entre as ocorrências nos demais horários. 


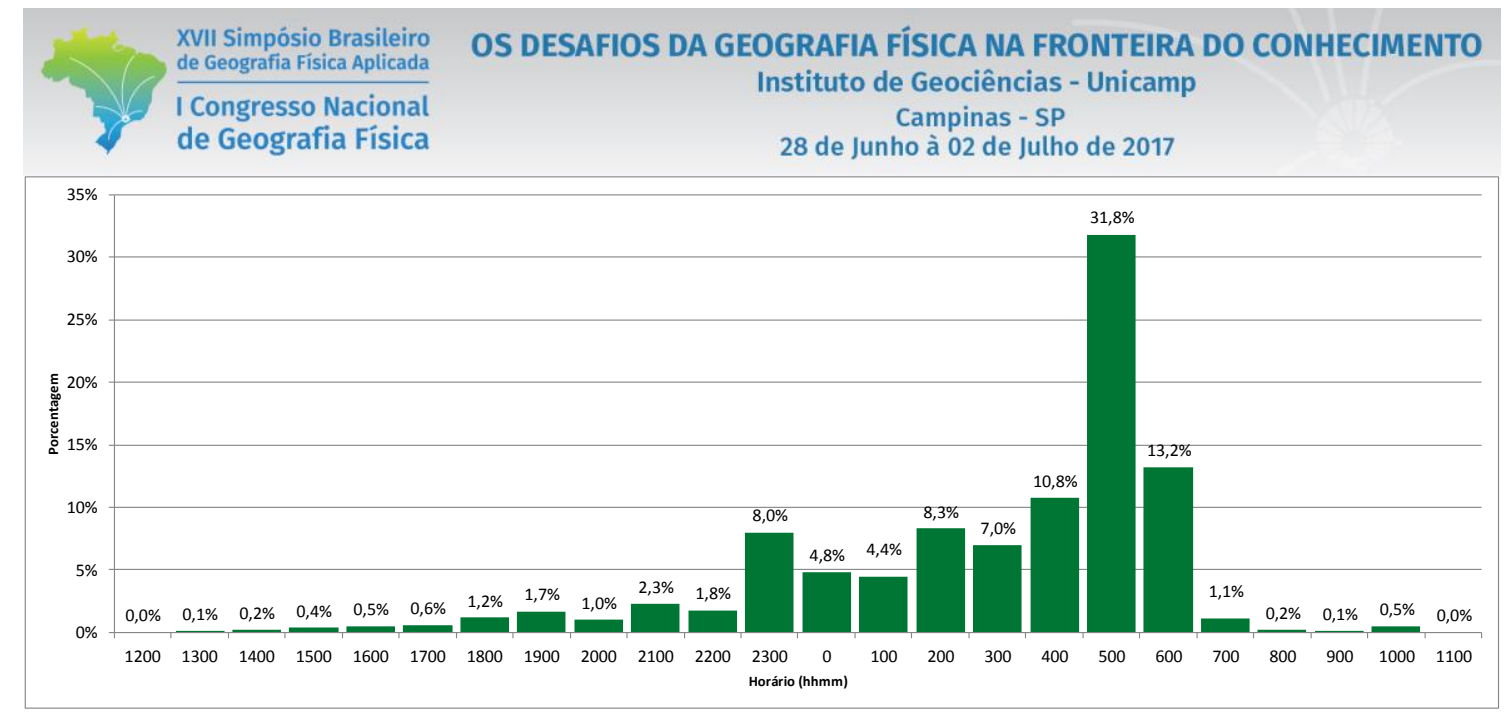

Figura 04: Percentual de ocorrências de temperaturas mínimas diárias na EMA do Departamento de Geografia (2008 a 2016), no período de verão.

No outono teve 1123 registros, com temperaturas mínimas ocorrendo em sua maior parte no horário das 6h00minàs 7h00min (27,4\%). Em seguida, os horáriosentre 5h00mine 6h00min $(21,1 \%)$ e 4 h00mine 5 h00min (11\%) foram aqueles de considerável concentração(Figura 05).

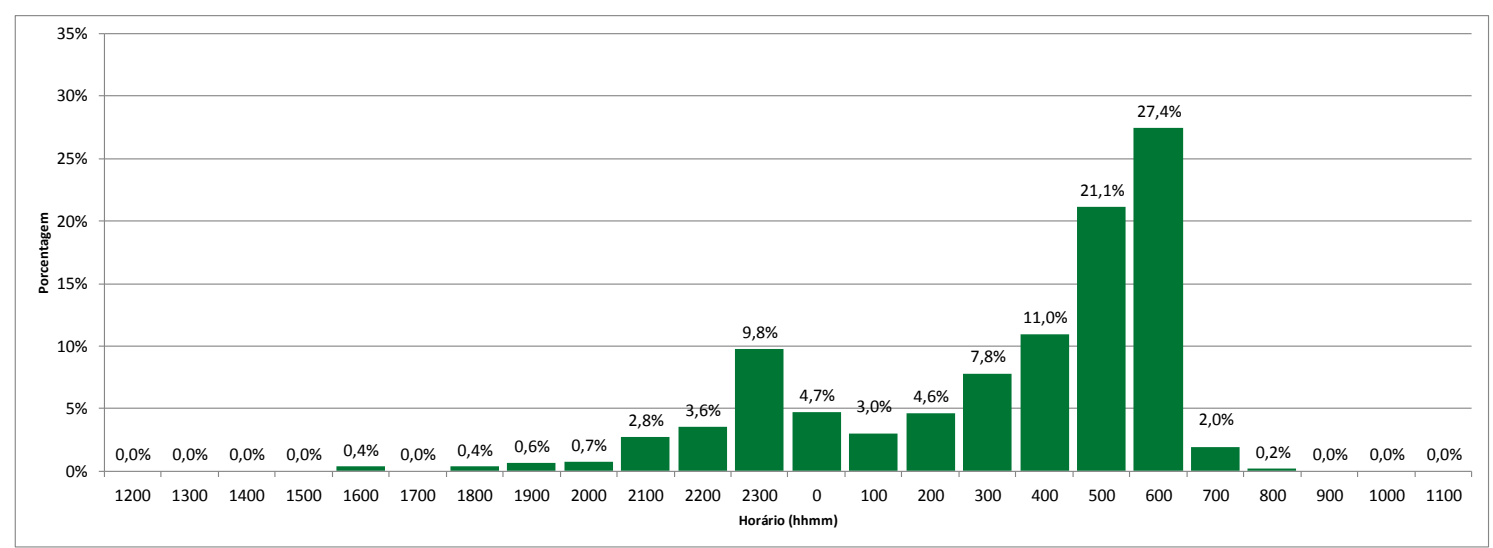

Figura 05: Percentual de ocorrências de temperaturas mínimas diárias na EMA do Departamento de Geografia (2008 a 2016) no período de outono.

No inverno houve 1367 registros, com predominância nos horários entre 6h00minàs 7h00min e 5h00mine 6h00min $(24,4 \%$ e $19,7 \%$ respectivamente). Das 23 h00min à 0 h00min, houve registros em $9,9 \%$ dos dias, conforme aponta a figura 06 . 


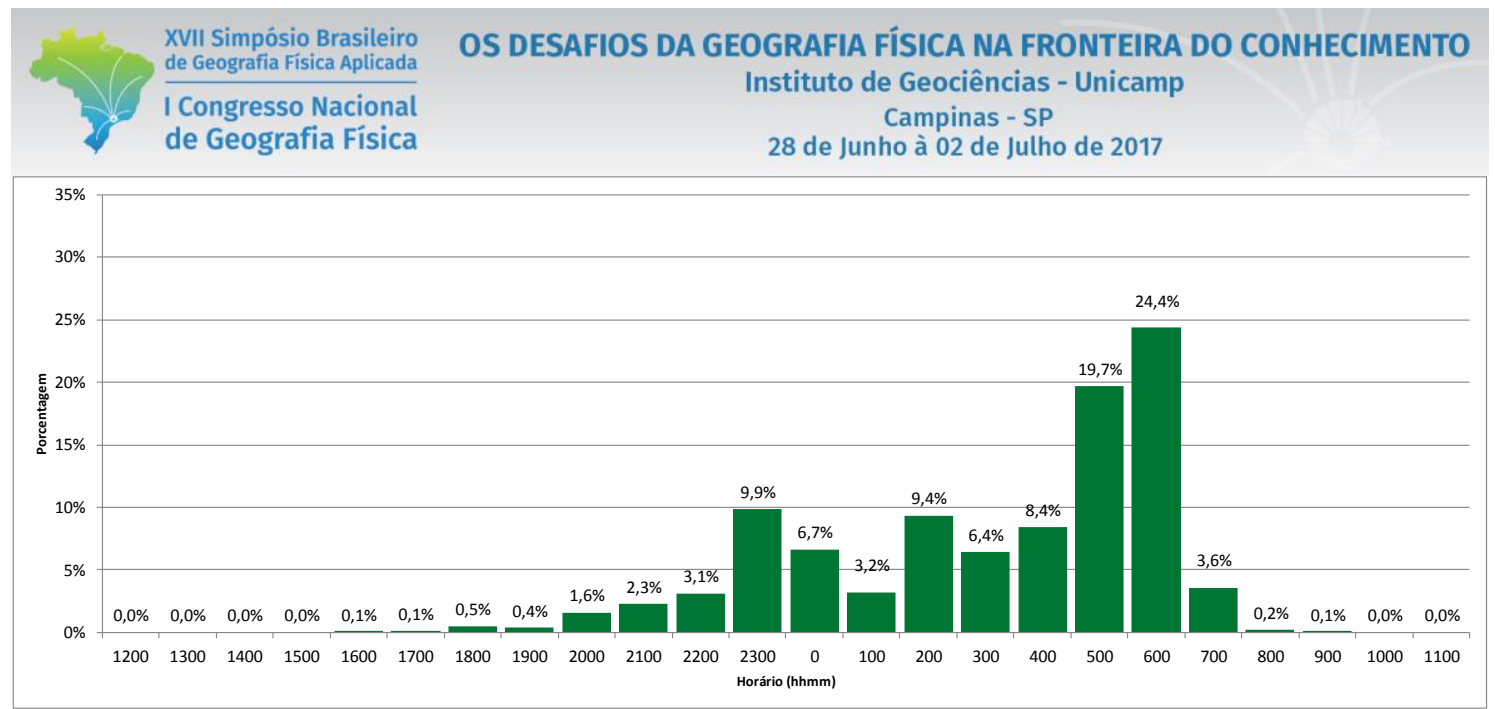

Figura 06: Percentual de ocorrências de temperaturas mínimas diárias na EMA do Departamento de Geografia (2008 a 2016) no período de inverno.

Lucas et al. (2011) identificam que, para a cidade de Santa Maria(RS), no outono e inverno, o horário de maior frequência é as 8 h00min. Já na primavera e verão, a frequência é maior às 6 h00 e 7h00min, respectivamente. Em noite atípicas é constatado a antecipação da ocorrência da temperatura mínima para qualquer horário noturno, devido a um aumento da velocidade do vento na maior parte dos casos (ocorrendo com frequencia maior no outono e inverno, nesta localidade).

Uma questão que se destaca, corroborada pela literatura, é a ocorrência de temperaturas mínimas absolutas no horário entre 23h00min e 00h00min tanto para os dados anuais $(10,1 \%)$, como para as analises sazonais (primavera com 11,9; o verão com 8,0; o outono com 9,8 e a estação de inverno com $9,9 \%$ das ocorrencias). Uma possível hipotese explicativa para essa ocorrência de temperaturas mínimas entre 23h00min e 00h00min é a proximidade do Oceano Atlântico (medida aproximada em linha reta em um perfil orientado NW a SE) com cerca de $50 \mathrm{~km}$ evidenciando o papel da brisa marítima e da maritimidade da área onde esta localizada aEMA.

\subsection{Estudo de evento}

Para um estudo de caso, analisou-se o período das 23 h00min às 0 h00min, uma vez que na amostragem dos dados nota-se uma ocorrência significativa de temperaturas mínimas nesta faixa horária, apesar da maior concentração de valores mínimos ao final da madrugada. Cerca de $25 \%$ dos dados registrados nesta faixa de horário ocorreram nos meses de novembro e dezembro (125 registros, de um total de 509).

Para isto, tomou-se a título de exemplo, o dia 04 de dezembro de 2016, no qual a temperatura mínima do ar do dia $\left(16,0^{\circ} \mathrm{C}\right)$ ocorreu em sete horários entre as $21 \mathrm{~h} 15 \mathrm{~min}$ e $23 \mathrm{~h} 55 \mathrm{~min}$. Nafigura 07 observa-se redução da temperatura a partir das 15h10min, acompanhada dedecréscimo da 
intensidade dos ventos. A temperatura apresentou redução de $10^{\circ} \mathrm{C}$ num intervalo de 3 horas $\left(29,5^{\circ} \mathrm{C}\right.$ para $\left.19,5^{\circ} \mathrm{C}\right)$.

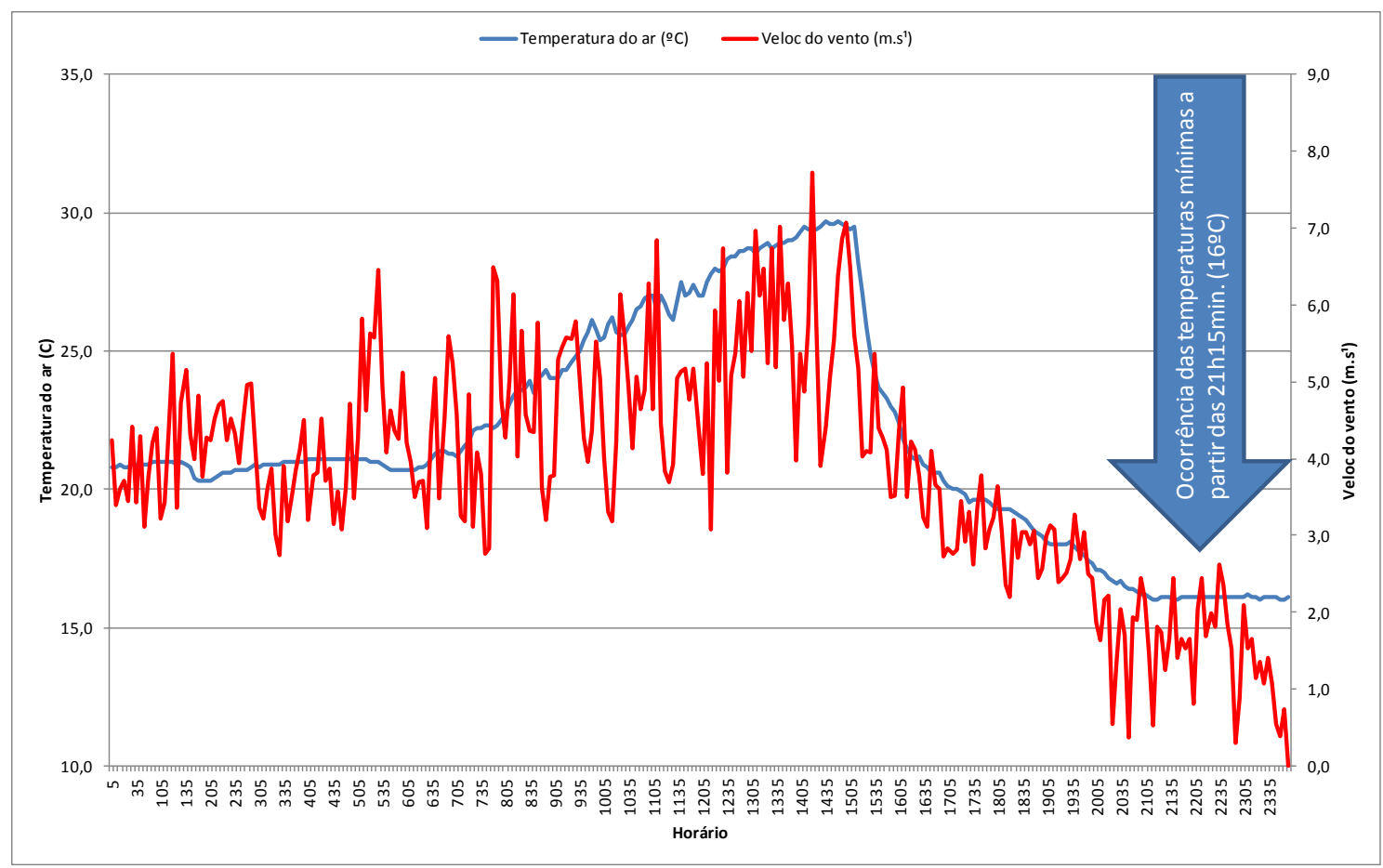

Figura 07: Relação entre a temperatura do ar e velocidade do vento (dia 04/12/2016) na EMA do Departamento de Geografia. Org. autores.

Na figura 08 é possível observar que a direção predominante do vento no dia 04/12/2016, do início do dia até a $15 \mathrm{~h} 15 \mathrm{~min}$ foi de NW e W. Após este horário, a direção passou a ter origem no quadrante SW-SE, com queda acentuada na velocidade dos ventos até o final do dia. 


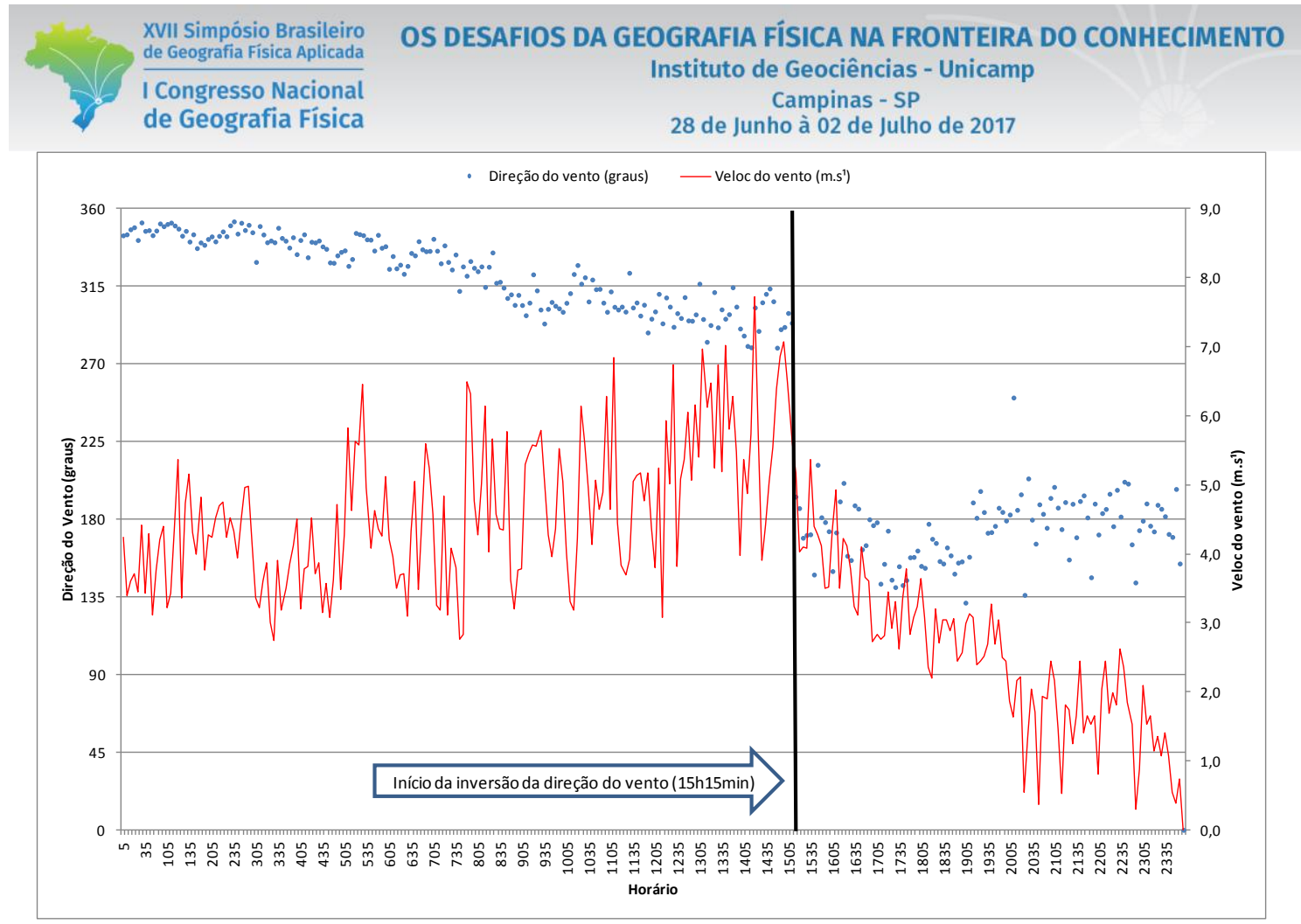

Figura 08: Direção e a velocidade do vento (dia 04/12/2016) na EMA do Departamento de Geografia. Org. autores.

Na figura 09, nota-se que a umidade relativa do ar tem um acréscimo a partir do período da tarde. Após as 15 h00min, há um acréscimo na umidade, de $40 \%$ (valor mais baixo no dia) para $81 \%$ às $16 \mathrm{~h} 15 \mathrm{~min}$. À noite, os valores ultrapassam 90\%, com chuva fraca a partir das $20 \mathrm{~h} 00 \mathrm{~min}$ (total de 5,4mm no dia).

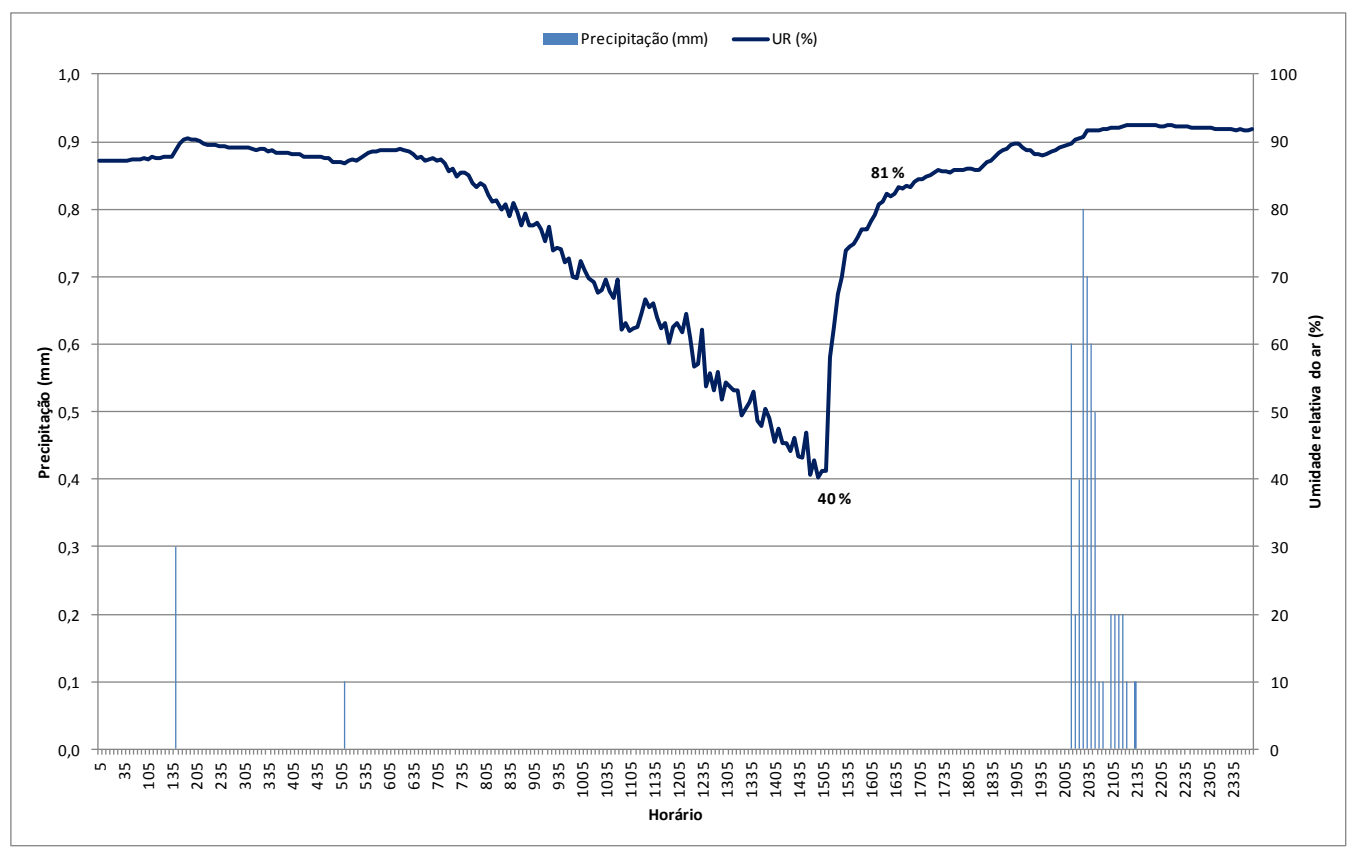

Figura 09: relação entre a umidade relativa do ar e precipitação (dia 04/12/2016) na EMA do Departamento de Geografia. Org. autores. 


\section{OS DESAFIOS DA GEOGRAFIA FISICA NA FRONTEIRA DO CONHECIMENTO Instituto de Geociências - Unicamp Campinas - SP \\ 28 de Junho à 02 de Julho de 2017}

Com estas informações, é possível afirmar que o avanço da brisa marítima na cidade de São Paulo foi o responsável pelo resfriamento ocorrido a partir do meio da tarde, registrado na EMA, e que resultou nas temperaturas mínimas absolutas ao final do dia.

$\mathrm{Na}$ análise das cartas sinópticas de superfície do CPTEC (Centro de Previsão de Tempo e Estudos Climáticos), para os dias 04 e 05 (00Z), é possível observar um centro de baixa pressão no litoral catarinense, que se aproxima do litoral de São Paulo ao longo do dia, contribuindo com acréscimo de umidade oriunda do oceano. Observa-se também a presença de uma Zona de Convergência de Umidade, atuando desde o noroeste do MT ao RJ e Oceano Atlântico adjacente. Porém, as chuvas acentuadas ocorreram somente na faixa oceânica (figura 10), manifestando-se na área de estudo como uma garoa moderada totalizando 5,4 mm.Ou seja, a redução da temperatura ao final do dia não ocorre devido à atuação de um sistema frontal e sim devido à brisa marítima.

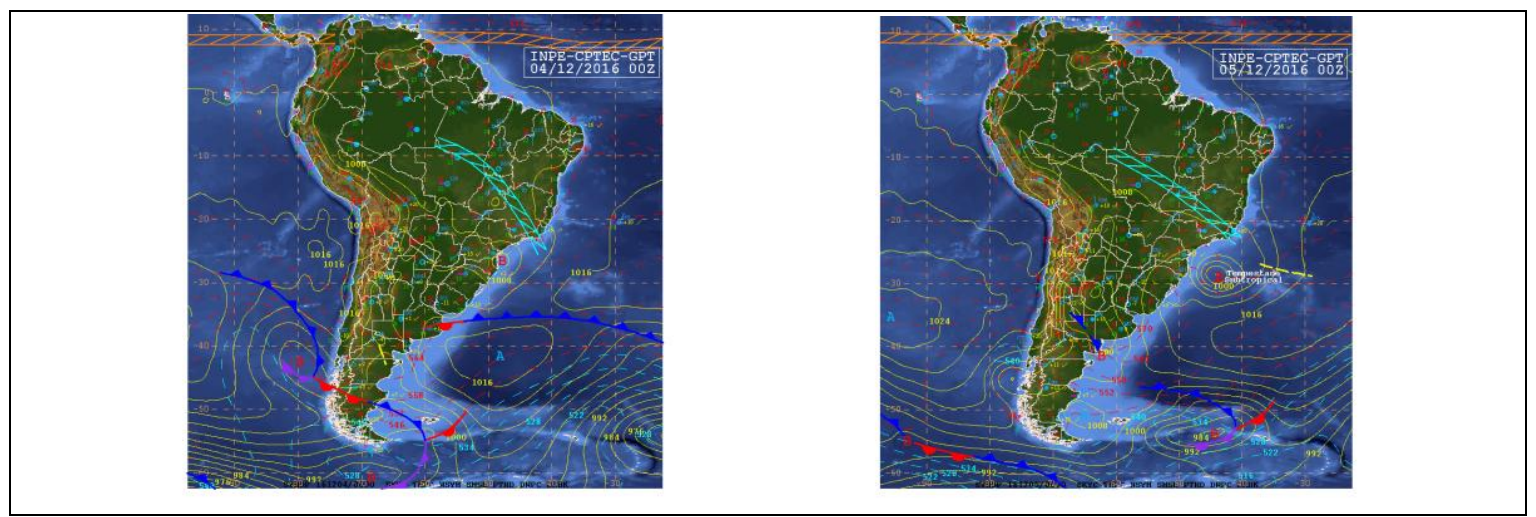

Figura 10: Cartas sinópticas de superfície para os dias 04 e 05 de dezembro de 2016. Fonte: CPTEC. Org. autores.

\section{Considerações Finais}

As temperaturas mínimas absolutas diárias, registradas na Estação Meteorológica Automática no período analisado de 2008 a 2016, apresentaram em sua distribuição horária ao longo do dia maior frequência durante o final da madrugada, especialmente no horário entre as 5 h00min e 6 h00min, em 23,5\% dos dados totais. No horário das 23 h00 às 0h00min há registros de temperaturas mínimas do ar em 10,1\% dos casos totais.Esta antecipação da temperatura mínima e resfriamento no final do dia pode ser explicado pelo avanço da brisa marítima, principalmente nos meses de final de primavera e início de verão.

Sazonalmente, na primavera e no verão, as maiores ocorrências foram entre 5 h00min e 6h00min. No outono e no inverno, as temperaturas mínimas ocorreram com maior frequência das 6h00min às 7h00min. 


\section{Referências}

BLAIN,G. C.; PICOLI, M. C. A.; LULU, J. Análises estatísticas das tendências de elevação nas séries anuais de temperatura mínima do ar no Estado de São Paulo.Bragantia, Campinas, v.68, n.3, p.807, 2009.

CAMARGO, M. B. P.; PEDRO JÚNIOR, M. J.; ALFONSI, R. R.; ORTOLANI, A. A.; BRUNINI, O. Probabilidade de ocorrência de temperaturas mínimas mensais e anual no Estado de São Paulo. Bragantia, Campinas, v.52, n.2, p.161-168, 1993.

DARONCO, F. R. ; RADONS, S. Z. ; KNAPP, F. M. ; COLETTO, I. B. . Horários de ocorrência das temperaturas máxima e mínima diárias do ar da estação meteorológica automática de Santo Augusto, RS. In: IV SEPE - Seminário de Ensino, Pesquisa e Extensão da UFFS, 2014, Cerro Largo. Anais..., 2014. v. 4.

GALVANI, E.; LIMA, N. G. B. de. Taxa de resfriamento noturno na cidade de São Paulo - SP: estudo de caso. In: Climatologia Aplicada: Resgate aos estudos de caso. Curitiba: Editora CRV, 2012, p. 55-66.

INSTITUTO NACIONAL DE METEOROLOGIA - INMET. 1992. Normais Climatológicas do Brasil. LÓPEZ, C. C. O vento. In TARIFA, J. R.; AZEVEDO, T.R. Os Climas na Cidade de São Paulo. GEOUSP 4, Pró-Reitoria de Cultura e Extensão Universitária. Universidade de São Paulo. 199 p., 2001.

LUCAS, D. D. P. ; RADONS, S. Z. ; RIGHI, E. Z. ; HELDWEIN, Arno Bernardo ; LOOSE, L. H. ; RAONS, M. Z. . Horário de ocorrência da temperatura mínima diária do ar em Santa Maria, RS. In: XVII Congresso Brasileiro de Agrometeorologia, 2011, Guarapari, ES. Congresso Brasileiro de Melhoramento de Plantas. Vitória, ES: Sociedade Brasileira de Agrometeorologia, 2011.

MONTEIRO, C. A de F.. Adinâmica climática e as chuvas do Estado de São Paulo: estudo em forma de Atlas. Instituto de Geografia, Universidade de São Paulo, 1973. 